\title{
Long-Term Depression of Excitatory Synaptic Transmission in the Rat Amygdala
}

\author{
Su-Jane Wang and Po-Wu Gean \\ Department of Pharmacology, College of Medicine, National Cheng-Kung University, Tainan, Taiwan 701
}

In view of the fact that both kindling and fear-potentiated startle are expressed by long-term enhancement of synaptic transmission in the amygdala, synaptic plasticity in this area of the brain is of particular importance. Here, we show for the first time that low-frequency stimulation of the lateral nucleus at $1 \mathrm{~Hz}$ for 15 min elicited a long-term depression (LTD) in the basolateral amygdala (BLA) neurons. LTD is expressed specifically at the lateral-BLA synapses but not at ventral endopyriform nucleusBLA synapses. The induction of LTD requires activation of both NMDA and metabotropic glutamate receptors. Loading cells with a $\mathrm{Ca}^{2+}$ chelator BAPTA or extracellular superfusion with

A wealth of data has established that the amygdala is critically involved in the neuronal plasticity, such as epilepsy and emotional memory (Goddard et al., 1969; McNamara, 1986; Davis et al., 1994). Two widely used animal models known to be related to the functions of amygdala are kindling and fear-potentiated startle. Kindling is the repeated administration of subconvulsive focal electrical stimuli to certain brain areas, which results in the progressive development of intense and generalized seizures (Goddard et al., 1969; McNamara, 1986). The amygdala is one of the most sensitive sites to induce kindling (Loscher et al., 1995). Fear-potentiated startle is an elevated startle amplitude in the presence of a cue previously paired with a shock. The amygdala receives input from sensory and associative cortex as well as nociceptive centers and sends output to autonomic centers in the hypothalamus and brainstem (LeDoux et al., 1990; Pitkanen et al., 1997). Thus, it evaluated the significance of external sensory stimuli to generate appropriate autonomic signs associated with emotional responses. In view of the fact that both kindling and fear-potentiated startle were expressed by long-term enhancement of synaptic transmission in the amygdala (Gean et al., 1989; Rainnie et al., 1992; Rogan et al., 1997; McKernan and ShinnickGallagher, 1997), synaptic plasticity in this area of the brain is of particular importance.

It is generally believed that long-term potentiation (LTP) and its inverse form long-term depression (LTD), functioning together, play a key role in various behaviors ranging from cortical arousal to learning and memory. Although several studies have described LTP in the amygdala (Chapman and Bellavance, 1992; Gean et al., 1993; Maren and Fanselow, 1995), virtually no LTD phenomenon has been reported. There was only one study in

\footnotetext{
Received Aug. 25, 1999; revised Oct. 4, 1999; accepted Oct. 6, 1999.

This study was supported by National Science Council of Taiwan Grant NSC88-2314-B006-021.

Correspondence should be addressed to Po-Wu Gean at the above address. E-mail: powu@mail.ncku.edu.tw.

Copyright (C) 1999 Society for Neuroscience 0270-6474/99/1910656-08\$05.00/0
}

protein phosphatase inhibitors prevents LTD, suggesting that LTD may result from dephosphorylation of AMPA receptors. The same stimulating protocol could not elicit LTD in neurons from kindled animals, whereas neurons from sham-operated or agematched control rats were able to exhibit LTD. Together, this study characterizes the properties of LTD in the naïve amygdala slices for the first time and demonstrates that epileptogenesis in vivo induces disruption of LTD in the in vitro preparation.

Key words: long-term depression; neuronal plasticity; amygdala; kindling; epilepsy; fear conditioning

which enduring synaptic depression did occur when the pathway was primed by a previous high-frequency stimulation (HFS) (Li et al., 1998). In the present study, we show the first evidence that LTD occurs in the naïve amygdala slices that is homosynaptic and pathway-specific. We further investigate the mechanisms underlying the induction and expression of LTD.

\section{MATERIALS AND METHODS}

Slice preparation. Male Sprague Dawley 4- to 6-week-old rats were decapitated, and their brains were rapidly removed and placed in cold oxygenated artificial CSF (ACSF) solution. Subsequently, the brain was hemisected and cut transversely posterior to the first branch and anterior to the last branch of the superior cerebral vein. The resulting section was glued to the chuck of a Vibroslice tissue slicer (Campden Instruments, Silbey, UK). Transverse slices of $500 \mu \mathrm{m}$ thickness were cut, and the appropriate slices were placed in a beaker of oxygenated ACSF at room temperature for at least $1 \mathrm{hr}$ before recording. ACSF solution had the following composition (in mM): $\mathrm{NaCl} 117, \mathrm{KCl} 4.7, \mathrm{CaCl}_{2} 2.5, \mathrm{MgCl}_{2} 1.2$, $\mathrm{NaHCO}_{3} 25, \mathrm{NaH}_{2} \mathrm{PO}_{4}$ 1.2, and glucose 11. The ACSF was bubbled continuously with $95 \% \mathrm{O}_{2}-5 \% \mathrm{CO}_{2}$ and had the $\mathrm{pH}$ of 7.4.

Intracellular recordings. A single slice was transferred to the recording chamber in which it was held submerged between two nylon nets and maintained at $32 \pm 1{ }^{\circ} \mathrm{C}$. The chamber consisted of a circular well of a low volume $(1-2 \mathrm{ml})$ and was perfused constantly at a rate of $2-3 \mathrm{ml} / \mathrm{min}$. Intracellular recording microelectrodes were pulled from $1.0 \mathrm{~mm}$ microfiber capillary tubing on a Brown-Flaming electrode puller (Sutter Instruments, San Rafael, CA). The electrodes were filled with 4 M potassium acetate with resistance ranging from 70 to $130 \mathrm{M} \Omega$. For chelating intracellular $\mathrm{Ca}^{2+}$, the electrodes were filled with $50 \mathrm{~mm}$ BAPTA in addition to $3 \mathrm{~m}$ potassium acetate. When BAPTA-containing electrodes were used, loading of the cells with BAPTA was assayed by the blockade of $\mathrm{Ca}^{2+}$-activated afterhyperpolarization and spike-frequency accommodation. The microelectrode tips were positioned into the basolateral subdivision of amygdala (BLA). Monosynaptic EPSPs were evoked in BLA neurons by electrical stimulation of afferents from the lateral (LA) nucleus of amygdala with a concentric bipolar stimulating electrode (SNE-100; Kopf Instruments, Bern, Germany). EPSPs were judged as monosynaptic because the latencies of EPSPs from onset of stimulation were constant with different stimulus intensities in a cell and were usually 2-5 msec. In some experiments, a second electrode was placed in the ventral endopyriform nucleus (VEN) (Fig. 1A). Electrical stimuli (150 $\mu \mathrm{sec}$ in duration) were delivered at a frequency of $0.05 \mathrm{~Hz}$. To induce 
A

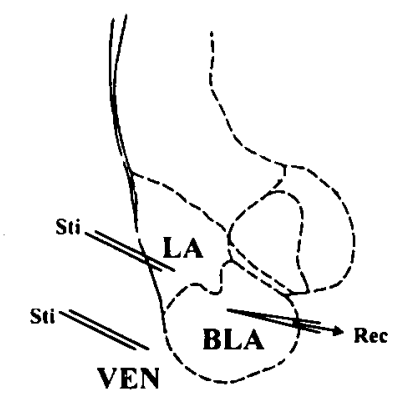

B
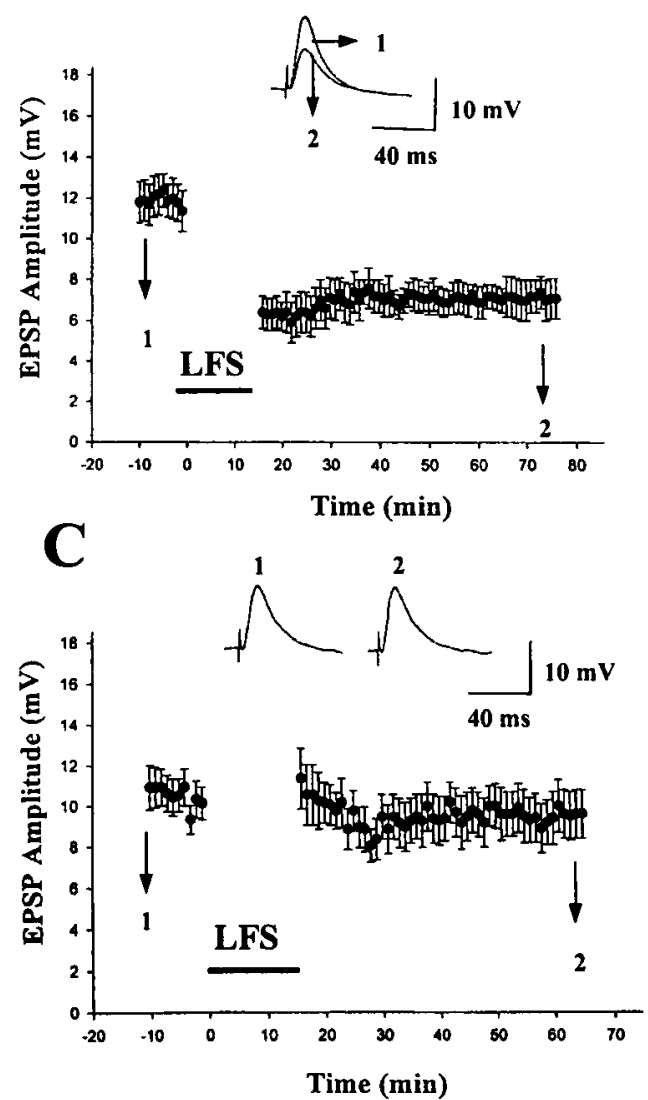

Figure 1. Amygdala LTD is pathway-specific. A, Schematic diagram of a coronal slice illustrating the positions of stimulating and recording electrodes. $B$, LTD induced by LFS in the lateral-BLA synapses. The graph represents the mean \pm SE amplitude of EPSPs $(n=16)$ plotted against time before and after LFS protocol. Inset shows the representative traces taken at the times indicated. $C$, No significant LFS-induced LTD was elicited by VEN stimulation $(n=9)$.

LTD, 900 pulses were delivered at $1 \mathrm{~Hz}$ at the same stimulation intensity used for baseline. All data were expressed as mean \pm SE. Statistical analysis was performed using the Student's $t$ test, and $p<0.05$ was considered statistically significant.

Kindling. Rats (4- to 6-week-old) were anesthetized with sodium pentobarbital $(35 \mathrm{mg} / \mathrm{kg}$, i.p.) and supplemented with ketamine hydrochloride $(40 \mathrm{mg} / \mathrm{kg}$, i.m.) if needed. Aseptic techniques were used throughout the surgical procedure. The skull was exposed, and holes for the electrodes were drilled with a dental burr. The stimulating electrodes consisted of a pair of stainless steel wires twisted tightly and insulated, except at the tips (Plastic Product Co., Roanoke, VA). The electrode was implanted stereotaxically in the left basolateral amygdala nucleus accord- ing to the coordinates of Paxinos and Watson (1982): $2.3 \mathrm{~mm}$ posterior and $8.5 \mathrm{~mm}$ ventral to bregma and $4.9 \mathrm{~mm}$ lateral to the midline and anchored to the skull with stainless steel screws and dental acrylate. Electrical stimulation of the amygdala was initiated after a postimplantation recovery period of at least $3 \mathrm{~d}$. The standard stimulus was $1 \mathrm{sec}$ in duration and $25 \mathrm{~V}$ in amplitude (Munkenbeck and Schwark, 1982), delivered once per day until kindling developed. Behavioral seizure severity was monitored using the ranking scale of Racine (1972). Fully kindled (three to five consecutive stage 5 kindled seizures) rats were rested for 3-7 d and then killed, and brain slices were made. Shamoperated rats were treated identically as the test animals and were implanted with electrodes but were not stimulated.

\section{RESULTS}

Figure $1 A$ illustrates the positions of the stimulating electrodes in the lateral nucleus and the $\mathrm{VEN}$ and the recording electrode in the BLA. The BLA receives intra-amygdala connections from the lateral nucleus (Stafanacci et al., 1992). There are also reciprocal connections between the BLA and the entorhinal and piriform cortices (Carlsen, 1989). Thus, by placing the stimulating electrode in the VEN, we targeted the path of fibers originating in the entorhinal and piriform cortices.

In an initial set of experiments, we examined whether prolonged (15 min) low-frequency stimulation (LFS) induced LTD at the BLA synapses. When the stimulation rate was increased from 0.05 to $1 \mathrm{~Hz}$, there was a rapid and pronounced frequency facilitation, followed by a depression below the baseline. Upon returning to $0.05 \mathrm{~Hz}$ after 900 pulses, synaptic responses remained depressed for the duration of experiments in 14 of 16 cells. The amplitudes of EPSP were $11.8 \pm 1.0 \mathrm{mV}$ in control and $7.1 \pm 1.0 \mathrm{mV} 60 \mathrm{~min}$ after stimulation $(n=16 ; p<0.001)$ (Fig. $1 B)$. In three cells, 6-cyano-7-nitroquinoxaline-2,3-dione $(10 \mu \mathrm{M})$ was applied at the end of experiments, which almost completely abolished the EPSP (data not shown), confirming that EPSP is mediated predominantly by the AMPA-kainate subtype of glutamate receptors. To test whether LFS-induced plasticity was restricted to lateral-BLA synapses, we repeated experiments by stimulating the VEN. As shown in Figure $1 C$, LFS of the VEN failed to induce LTD. The amplitudes of EPSP were $10.1 \pm 0.9$ $\mathrm{mV}$ before and $9.6 \pm 1.0 \mathrm{mV}(n=9 ; p>0.3) 60 \mathrm{~min}$ after stimulation.

To ensure the independence of the two inputs, we performed homosynaptic and heterosynaptic paired-pulse stimulation. Homosynaptic stimulation referred to the delivery of paired stimuli to one input, whereas heterosynaptic stimulation was delivered by stimulating one input shortly before the second. Figure $2 A$ shows that homosynaptic stimulation resulted in paired-pulse facilitation (PPF) in each pathway. The PPF ratios were $1.54 \pm 0.05(n=$ $6)$ and $1.34 \pm 0.04(n=6)$ in lateral-BLA and VEN-BLA synapses, respectively. In contrast, heterosynaptic stimulation did not cause PPF (PPF ratio was $1.01 \pm 0.03 ; n=6 ; p<0.01$ ), indicating the independence of two pathways (Fig. 2B). This conclusion was reinforced by the linear summation of two independent excitatory inputs. EPSPs evoked by each input were measured separately and then elicited simultaneously and compared with their expected sum. As revealed in Figure $2 C$, the summation was compatible to the arithmetic sum of the individual events $(101 \pm 6 \%$ of expected; $n=6)$.

No demonstratable changes in either resting membrane potential $(-65 \pm 2 \mathrm{vs}-64 \pm 1 \mathrm{mV}$ in the control and after LTD; $n=$ 8 ) or passive membrane properties ( $44 \pm 4$ vs $42 \pm 4 \mathrm{M} \Omega$ in the control and after LTD; $n=8$ ) were noted after conditioning (Fig. 3). To test whether the expression of LTD was presynaptic in origin, PPF, which is a widely accepted index of presynaptic 
A

VEN paired

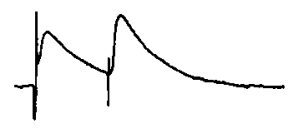

Lateral paired

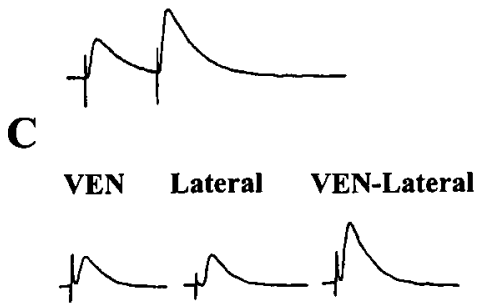

B

VEN

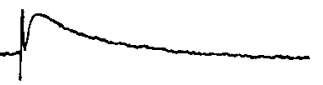

Lateral

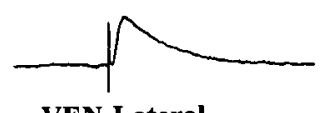

VEN-Lateral
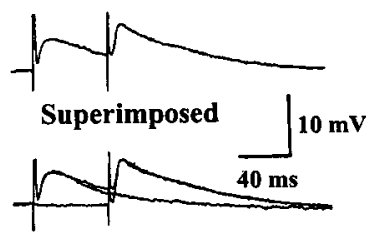

Figure 2. Independence of the VEN-BLA and lateral-BLA pathways. $A$, A pair of stimulations delivered to the VEN and lateral nucleus, respectively, showing that both pathways exhibited homosynaptic PPF. B, No heterosynaptic PPF was observed when stimuli were delivered in sequence to each pathway with an interval of $60 \mathrm{msec}$. $C$, Summation of EPSPs when stimulation was delivered to both pathways simultaneously.

phenomenon (Manabe et al., 1993; Schulz et al., 1994), was measured before and after LFS. At $60 \mathrm{~min}$ after stimulation, there was no change in PPF. The ratio of PPF was $1.50 \pm 0.15$ before and $1.38 \pm 0.10$ after $(n=7 ; p=0.5)$ conditioning, suggesting that the effect was not caused by a change in the presynaptic glutamate release probability.

To further assess whether LTD was restricted only to the synapse that received LFS, we performed a two-pathway experiment in which we measured, in the same BLA neuron, both VEN EPSPs and lateral EPSPs. The results of these experiments are shown in Figure $4 A$. LFS of lateral nucleus produced LTD of the lateral EPSP specifically (control: $9.3 \pm 1.4 \mathrm{mV}$; 60 min after conditioning: $5.9 \pm 0.9 \mathrm{mV} ; n=6 ; p<0.001$ ), without affecting the VEN EPSP (control: $9.7 \pm 1.7 \mathrm{mV} ; 60$ min after conditioning: $9.9 \pm 1.9 \mathrm{mV} ; n=6 ; p=0.44)$ (Fig. $4 A$ ). On the other hand, LFS of VEN had no significant effects on both lateral EPSPs (control: $11.8 \pm 1.4 \mathrm{mV} ; 60 \mathrm{~min}$ after conditioning: $11.6 \pm 1.5 \mathrm{mV} ; n=6$; $p=0.57$ ) and VEN EPSPs (control: $10.3 \pm 1.0 \mathrm{mV} ; 60 \mathrm{~min}$ after conditioning: $10.5 \pm 0.9 \mathrm{mV} ; n=6 ; p=0.5$ ) (Fig. $4 B$ ). These results suggest that the LTD in BLA is input-specific; only LABLA synapses receiving the low-frequency conditioning stimulation show LTD.

The induction of LTD in hippocampal CA1 neurons requires the activation of NMDA receptors (Dudek and Bear, 1992; Mulkey and Malenka, 1992). However, subsequent studies in CA1 and other areas have revealed that LTD also depends on the activation of metabotropic glutamate receptors (mGluRs) (Kato, 1993; Bolshakov and Siegelbaum, 1994; Oliet et al., 1997). Therefore, it is of interest to assess whether LFS-induced LTD in the amygdala was sensitive to NMDA or mGluR blockade. In nine experiments, the slices were perfused with $50 \mu \mathrm{M}$ D-2-amino-5phosphonovalerate (D-APV), and 900 pulses were delivered at 1 $\mathrm{Hz}$. The results in Figure $5 A$ demonstrate that D-APV completely blocked the induction of LTD. The amplitudes of EPSPs were $11.7 \pm 0.7 \mathrm{mV}$ before and $11.8 \pm 0.9 \mathrm{mV} 60 \mathrm{~min}$ after $(n=9, p=$ 0.34 ) conditioning. In five cells, after D-APV washout, in each of these cells, subsequent LFS elicited LTD (control EPSP: $10.8 \pm$ $0.9 \mathrm{mV} ; 60 \mathrm{~min}$ after LFS: $7.4 \pm 0.9 \mathrm{mV} ; n=5)$. These results

A

\section{Control}
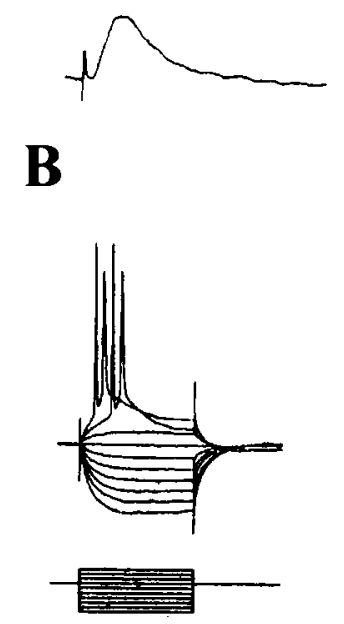

C

\section{LFS 40 min}
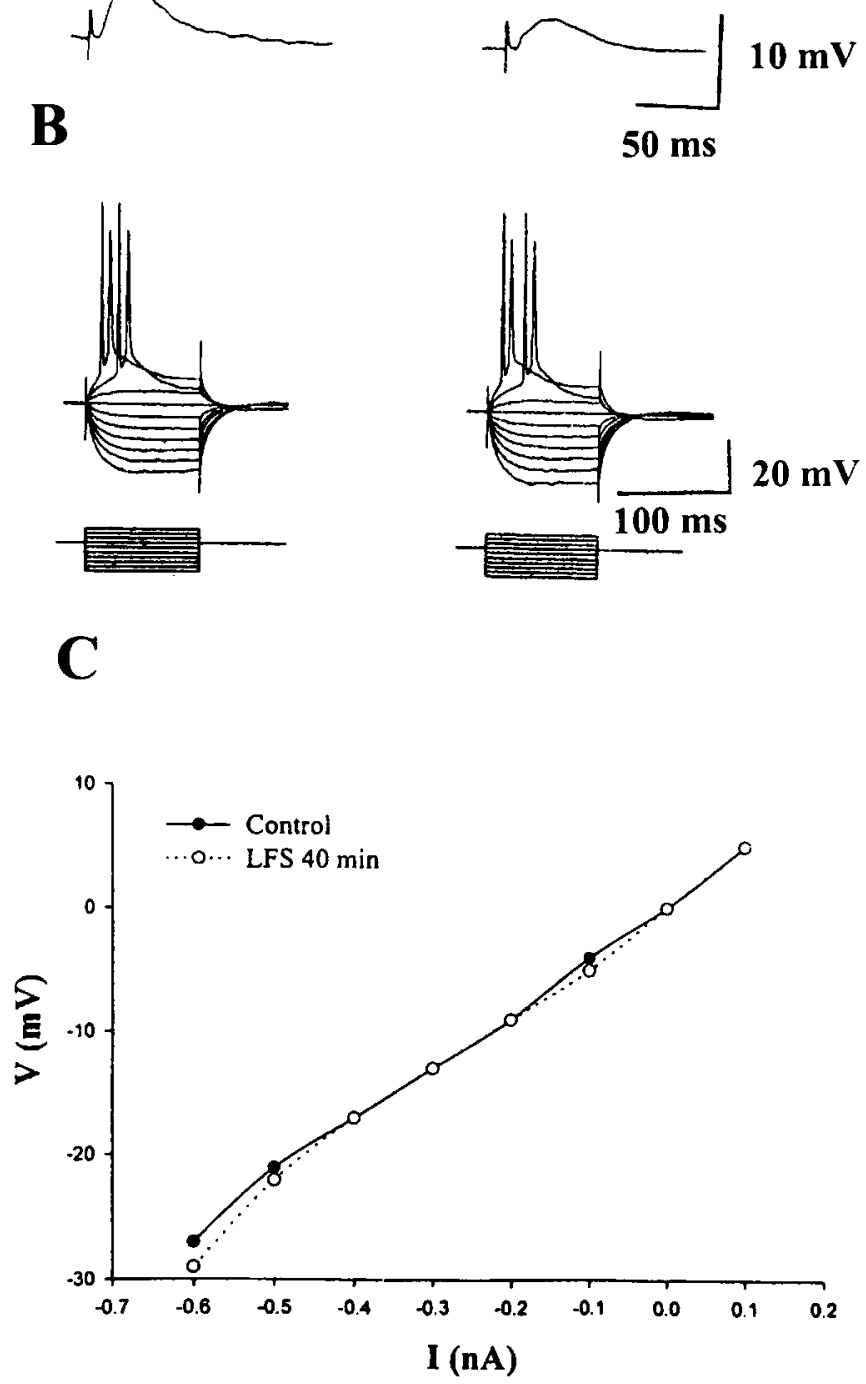

Figure 3. LTD is not associated with changes in passive membrane properties. $A$, Synaptic responses recorded before and $40 \mathrm{~min}$ after LFS in a BLA neuron. $B$, Electrotonic potentials recorded as a result of anodal and cathodal currents passed across the membrane before and after conditioning. $C$, Current-voltage relationship showing that conditioning did not affect passive membrane properties. All records were taken from the same neuron.

suggest that induction of amygdala LTD requires activation of NMDA receptors.

To examine the involvement of $\mathrm{mGluR}$, the mGluR antagonist ( \pm )-amino-4-carboxy-methyl-phenylacetic acid (MCPG) (500 $\mu \mathrm{M}$ ) was applied for $10 \mathrm{~min}$ before and during LFS. As shown in Figure 5B, MCPG completely blocked LFS-induced LTD in the amygdala. The amplitudes of EPSPs were $12.8 \pm 0.5 \mathrm{mV}$ in control and $12.3 \pm 0.8 \mathrm{mV} 60 \mathrm{~min}$ after stimulation $(n=7 ; p=0.33)$.

Activation of NMDA receptors allows $\mathrm{Ca}^{2+}$ influx into postsynaptic cells. To determine whether a rise in postsynaptic $\mathrm{Ca}^{2+}$ is required for LTD induction, the cells were recorded with 

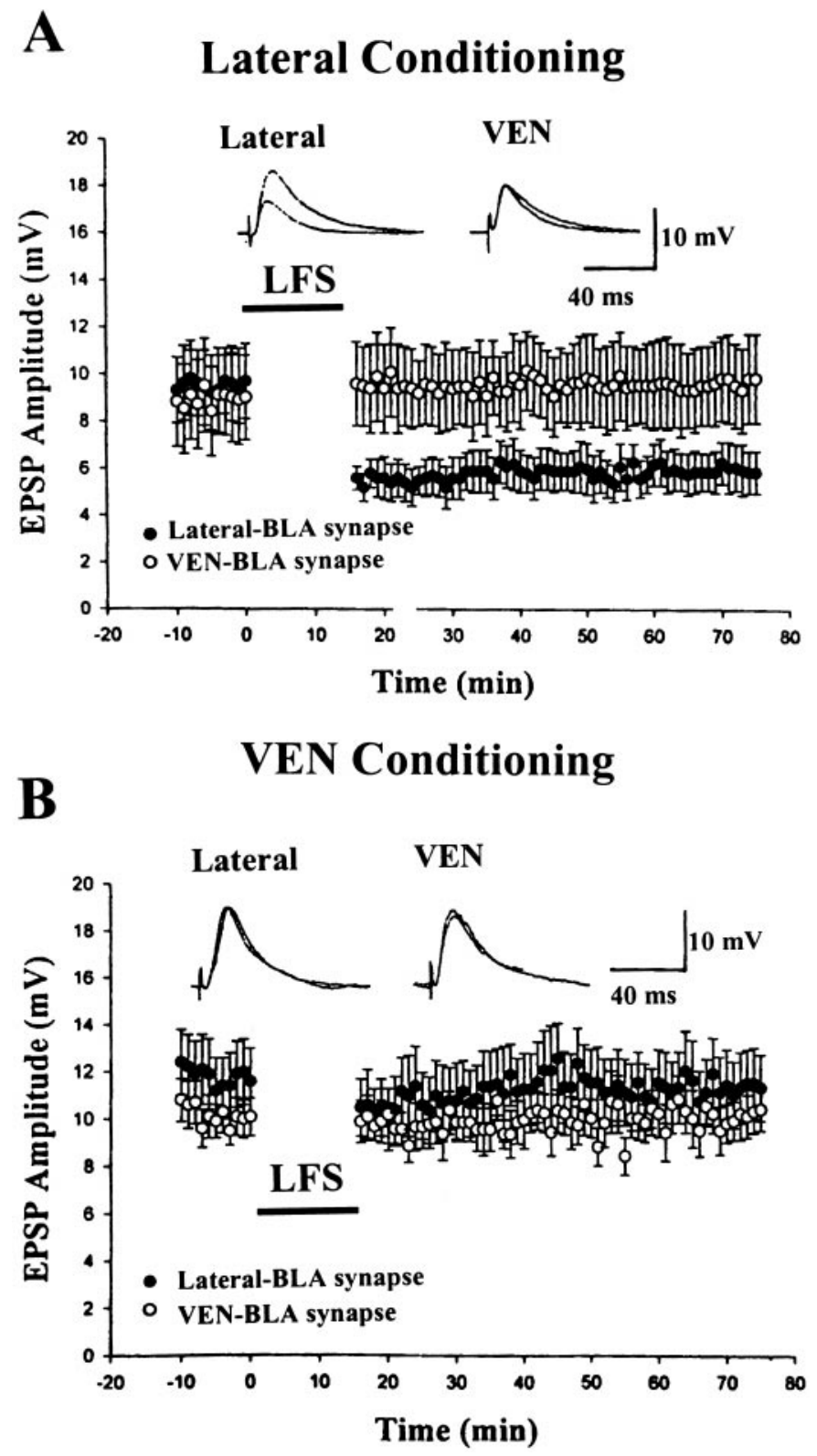

Figure 4. Amygdala LTD is homosynaptic. $A$, The graph illustrates the effect of LFS given to the lateral nucleus on the lateral $(n=6)$ and VEN $(n=6)$ EPSPs. LTD occurred only in the input receiving LFS. $B$, LFS given to the VEN affected neither VEN-BLA $(n=6)$ nor lateral-BLA $(n=6)$ synapses. Each point represents the mean \pm SE.

BAPTA-containing (50 mM) microelectrodes. After impalement, the cells were allowed to stabilize for at least $30 \mathrm{~min}$ to allow the cell to fill with BAPTA, which was manifested by blockade of slow afterhyperpolarization. Baseline responses were then obtained for an additional $10 \mathrm{~min}$ before LFS was delivered. As illustrated in Figure 6, LFS failed to induce LTD under this condition. The amplitudes of EPSPs were $10.6 \pm 1.8$ in control and $10.9 \pm 1.8 \mathrm{mV}$ after $(n=7 ; p=0.3)$ conditioning. This result provides evidence of a postsynaptic mechanism in the induction of amygdala LTD.

One likely signal pathway, which is $\mathrm{Ca}^{2+}$-dependent and may be involved in LTD induction, is protein phosphatase cascade (Mulkey et al., 1993). We examined whether amygdala LTD is associated with change in phosphatase activity by application of
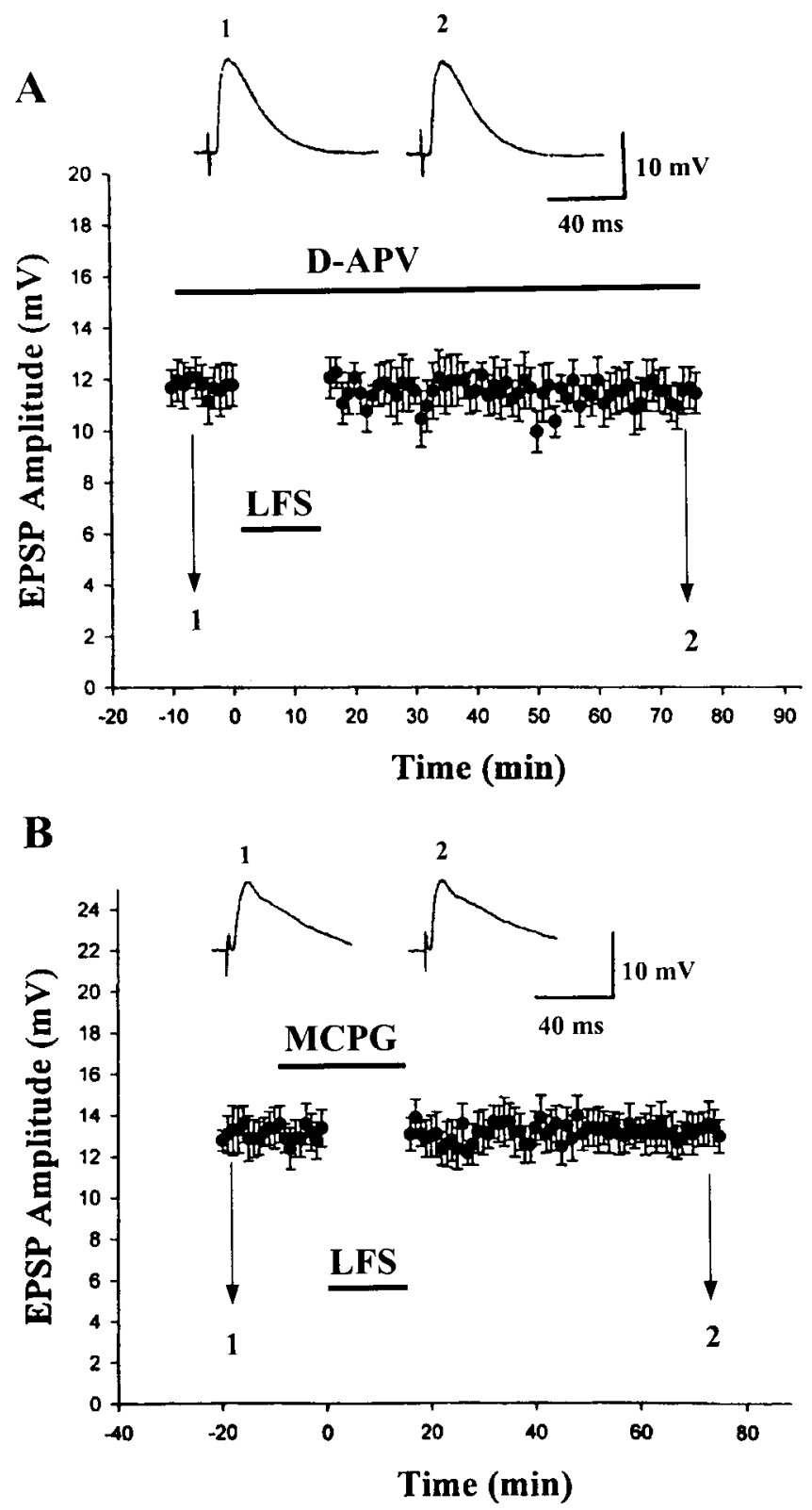

Figure 5. LTD induction requires activation of both NMDA receptors and mGluRs. $A$, In the presence of D-APV $(50 \mu \mathrm{M})$, LFS failed to produce LTD $(n=7)$. $B$, LFS protocol delivered in the presence of MCPG $(500$ $\mu \mathrm{M})$ failed to induce $\operatorname{LTD}(n=7)$. Each point represents the mean $\pm \mathrm{SE}$.

specific protein phosphatase inhibitors. Figure $7 A$ shows that okadaic acid $(1 \mu \mathrm{M})$, a specific inhibitor of protein phosphatases 1 and 2A (PP1 and PP2A), completely blocked LTD. The EPSP amplitudes were $12.0 \pm 1.2 \mathrm{mV}$ in control, $12.3 \pm 1.3 \mathrm{mV}$ in the presence of okadaic acid, and $12.7 \pm 1.5 \mathrm{mV} 60 \mathrm{~min}$ after conditioning $(n=6)$. Similarly, calyculin A $(1 \mu \mathrm{M})$, which is structurally distinct from okadaic acid and is a more potent inhibitor of PP1 and PP2A, also blocked the generation of LTD completely. The EPSP amplitudes were $9.8 \pm 1.0 \mathrm{mV}$ in control, $9.6 \pm 0.8 \mathrm{mV}$ in the presence of calyculin $\mathrm{A}$, and $10.4 \pm 1.6 \mathrm{mV}$ 60 min after conditioning $(n=6)$ (Fig. $7 B)$.

Kindling refers to the progressive development of partial and generalized seizures resulting from repeated subconvulsive electrical stimuli to the amygdala (Goddard et al., 1969). We exam- 


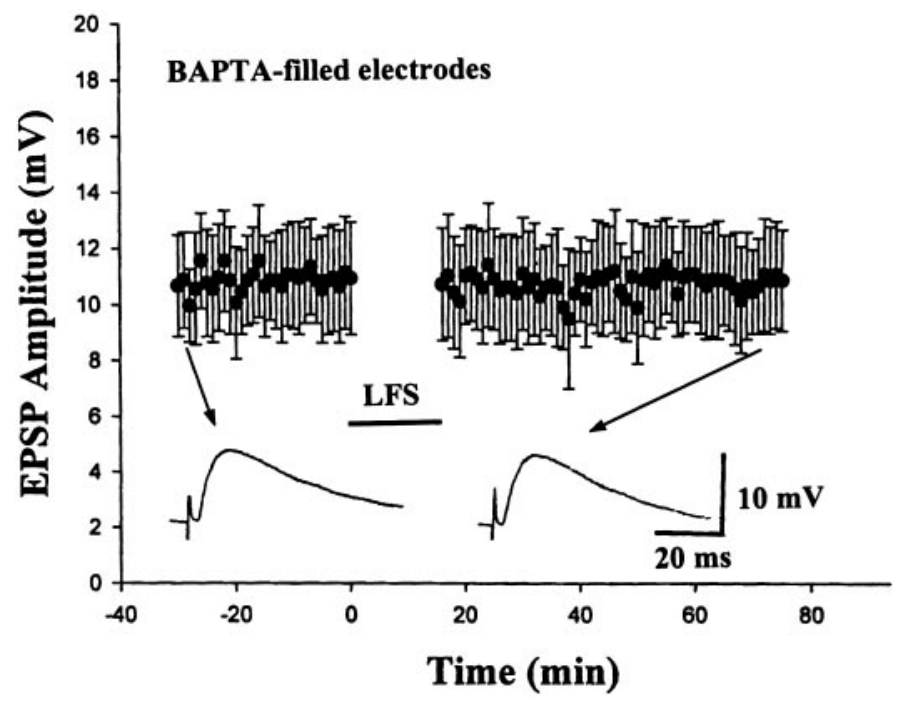

Figure 6. LTD induction requires a rise in postsynaptic $\mathrm{Ca}^{2+}$. Inclusion of BAPTA $(50 \mathrm{mM})$ in the recording electrodes blocked the generation of LTD $(n=7)$. Each point represents the mean \pm SE.

ined whether LFS could induce LTD and attenuate the bursting activity in 12 slices from nine kindled rats. Figure $8 A$ shows that LFS induced an initial depression of EPSP, which recovered to $92 \pm 4 \%$ (control: $11.0 \pm 0.7 \mathrm{mV} ; 60$ min after stimulation: $10.1 \pm$ $0.8 \mathrm{mV} ; n=12$ ) of control 60 min after the conditioning in BLA neurons of kindled animals. The inability of kindled animals to support LTD could be because of the age of animals. We tested this possibility by delivering LFS to the sham-operated and agematched (7- to 9-week-old) control rats. As illustrated in Figure $8 A$, the magnitude of initial depression $(-18 \pm 6 \% ; n=12)$ in kindled rats was significantly less than those of sham-operated $(-32 \pm 7 \% ; n=12)$ and age-matched $(-31 \pm 10 \% ; n=9)$ animals. In the same way, the levels of LTD were $-23 \pm 4 \%(n=$ $12)$ in sham-operated and $-24 \pm 6 \%(n=9)$ in age-matched rats, which differed significantly from that of kindled animals $(-8 \pm$ $4 \% ; n=12 ; p<0.01$ vs sham-operated or age-matched groups), respectively. It is noted that the magnitudes of LTD in shamoperated and age-matched controls was significantly less than that of in young controls $(-40.4 \pm 10.0 \% ; n=16 ; p<0.01$ vs sham-operated or age-matched controls).

Finally, as reported previously (Gean et al., 1989; Rainnie et al., 1992), stimulation of lateral nucleus in some BLA neurons of kindled rats readily evoked a burst of action potentials. In eight of these neurons, LFS protocol was delivered and was found to have little, if any, effect on the bursting activity (Fig. 8B).

\section{DISCUSSION}

\section{Properties of amygdala LTD}

A characteristic of synaptic plasticity in the mammalian CNS is that the strength of synaptic transmission can be enhanced or attenuated by varying the stimulation frequency and duration. Thus, brief HFS typically caused LTP, whereas prolonged LFS resulted in LTD (Bliss and Collingridge, 1993). In the amygdala, it has been shown recently that LFS of external capsule did not produce LTD but, instead, induced LTP. Persistent depression was seen only when the pathway was primed by a previous HFS, suggesting that the history of synaptic activity rather than the frequency determines the direction of synaptic plasticity (Li et al., 1998). In the present study, we have demonstrated for the first
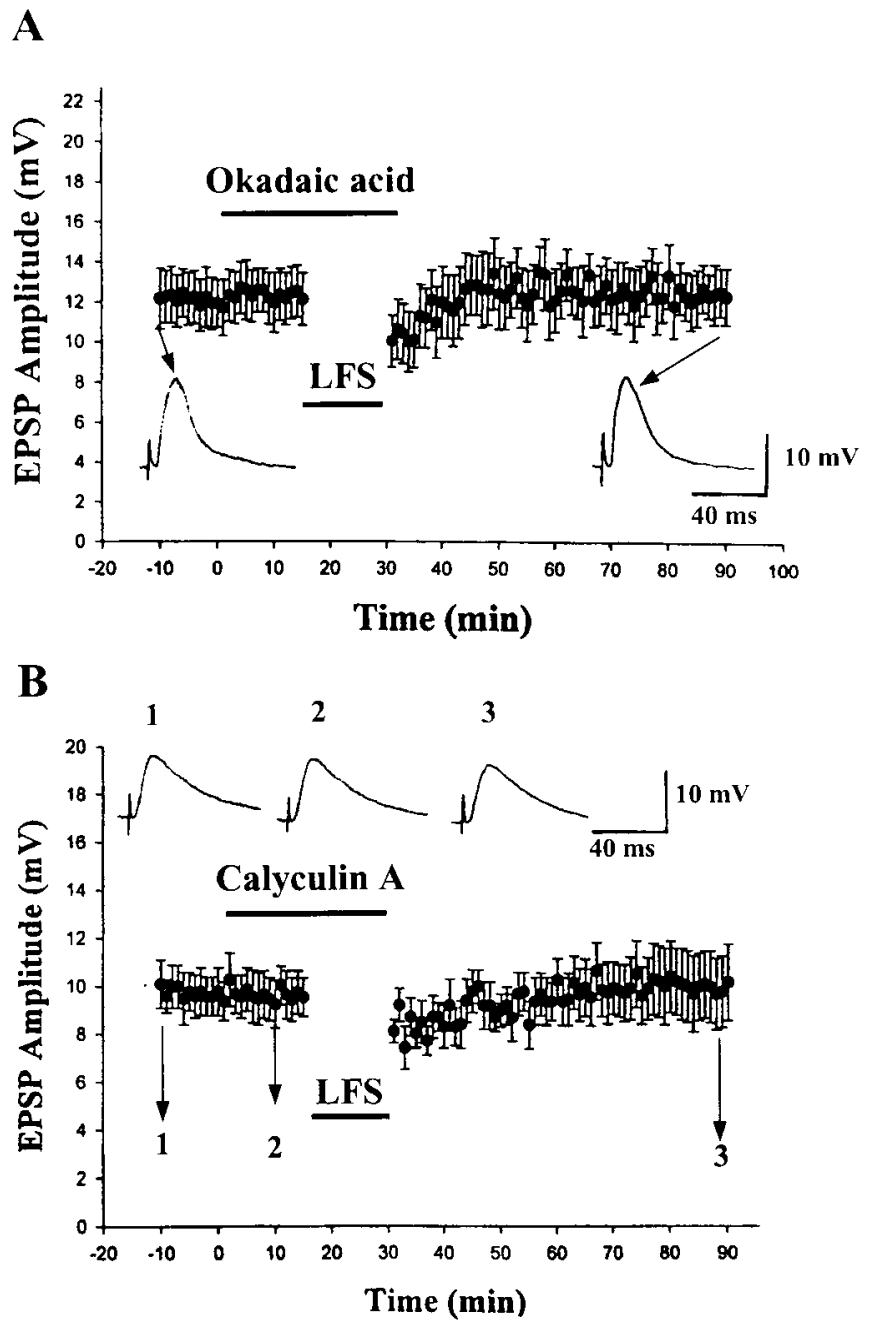

Figure 7. Effects of protein phosphatase inhibitors on the LTD. $A$, Okadaic acid $(1 \mu \mathrm{M})$ on its own did not significantly affect synaptic responses. However, in the presence of okadaic acid, LFS did not produce LTD $(n=6)$. $B$, Calyculin A $(1 \mu \mathrm{M})$ had no effect on the EPSP but inhibited LTD $(n=6)$. Each point represents the mean \pm SE.

time that LTD occurs in the naïve amygdala slices. LFS of the lateral nucleus reliably produced a sustained depression, whereas conditioning the VEN failed to induce LTD, indicating that it is pathway-specific. In addition, only synapses receiving the conditioning stimulation showed LTD and other input converging onto the same postsynaptic neuron was unaffected.

Cortical fibers enter the BLA primarily through external capsule. Autoradiographic and horseradish peroxidase studies have revealed that neurons projecting to the BLA are found in the medial frontal, perirhinal, and entorhinal cortices (Ottersen, 1982; Carlsen, 1989). The LA nucleus receives fibers from neocortical areas associated with visual, auditory somatosensory, and viscerosensory modalities (LeDoux et al., 1990). These fibers also enter the LA coursing through the external capsule. Thus, stimulation in the external capsule could excite BLA neurons directly via monosynaptic connection or indirectly through activation of LA neurons, which in turn excites BLA neurons via LA-BLA connections. Therefore, the difference between the results of $\mathrm{Li}$ et al. (1998) and ours could be attributed to the different set of pathways stimulated.

The reason for the differential capacity of LTD induction 
$\mathbf{A}$

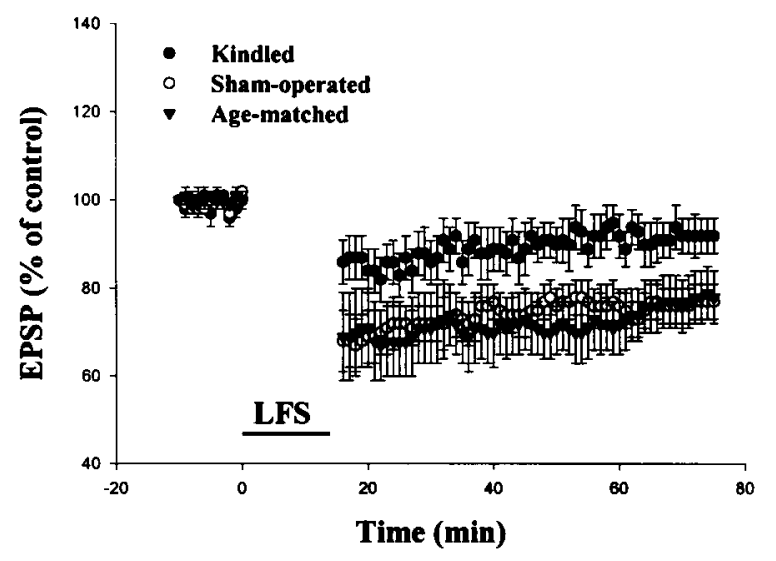

B

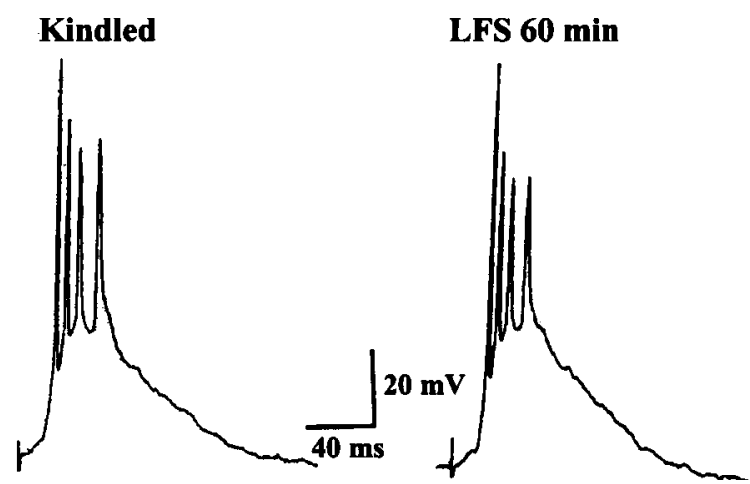

Figure 8. Loss of LTD in slices from kindled animals. A, LFS protocol induced a significant depression in 12 slices from seven sham-operated and nine slices from six age-matched control rats (7- to 9-week-old), respectively. In contrast, the magnitude of depression was markedly reduced in 12 slices from nine kindled animals (7- to 9-week-old). Each point represents the mean \pm SE. $B$, Representative traces showing that LFS had little effect on the bursting activity recorded in eight slices from five kindled animals.

among LA-BLA, VEN-BLA, and external capsule-BLA synapses is not known. One possibility is the differential expression of NMDA receptor-mediated synaptic currents between these two pathways. In this respect, it has been shown that there were distinct populations of NMDA receptors at cortical and thalamic inputs to the lateral amygdala neurons (Weisskopf and LeDoux, 1999).

A difference in the magnitude of LTD between juveniles and more mature animals was noted. The level of depression was higher in juveniles compared with those of adult rats. This is consistent with the observation in the hippocampus in which the homosynaptic LTD is more reliably induced in younger animals compared with adult rats (Wagner and Alger, 1995).

\section{Induction mechanism}

We have demonstrated that an elevation of postsynaptic $\mathrm{Ca}^{2+}$ was required for the genesis of lateral-BLA LTD, because buffering intracellular $\mathrm{Ca}^{2+}$ with $\mathrm{Ca}^{2+}$ chelator prevented LTD. The involvement of NMDA receptors suggested that $\mathrm{Ca}^{2+}$ influx through NMDA channels played an important role. Interestingly, LTD could also be blocked by a mGluR antagonist MCPG, indicating that amygdala LTD required the conjoint activation of mGluRs and influx of $\mathrm{Ca}^{2+}$ through NMDA receptors. The mechanism by which antagonism of mGluRs blocks induction of LTD is not clear. However, a hallmark of NMDA receptordependent synaptic plasticity is its need for neuronal depolarization. In BLA neurons, activation of mGluRs produced a membrane depolarization that was mediated by activation of $\mathrm{Na}^{+}$$\mathrm{Ca}^{2+}$ exchange activity (Keele et al., 1997). Thus, it is likely that mGluR-mediated depolarization enhances NMDA responses by removing $\mathrm{Mg}^{2+}$ block of NMDA channels, allowing $\mathrm{Ca}^{2+}$ permeation and consequent activation of intracellular $\mathrm{Ca}^{2+}$ dependent processes. This is in agreement with the notion that increasing NMDA receptor activation facilitates the induction of LTD (Kerr and Abraham, 1995; Wagner and Alger, 1995). MCPG is a specific antagonist of the group I/II mGluRs. Activation of group I mGluRs causes a rise in intracellular $\mathrm{Ca}^{2+}$ by stimulating phosphoinositide hydrolysis and the production of $\mathrm{IP}_{3}$ (Houamed et al., 1991; Masu et al., 1991). Therefore, another possibility could be attributable to the block of MCPG of intracellular $\mathrm{Ca}^{2+}$ release induced by activation of group I mGluRs.

The requirement of coactivation of mGluRs and NMDA receptors to induce amygdala LTD described here is clearly different from those in the hippocampal CA1 neurons in which LTD induction required either $\mathrm{mGluR}$ or NMDA receptor activation. One type, which was NMDA receptor-dependent and mGluRindependent, involved protein phosphatase activation and was induced and expressed postsynaptically. A second type, which was mGluR-dependent and NMDA receptor-independent, was insensitive to phosphatase inhibitors and was induced postsynaptically but expressed presynaptically (Oliet et al., 1997). However, an essential role for both mGluRs and NMDA receptors in the induction of LTD has been described in the immature hippocampal CA1 neurons (Overstreet, 1997).

\section{Expression mechanism}

Changes in the degree of PPF are assumed to reflect modifications in presynaptic release probability (Zucker, 1989). Amygdala LTD was not accompanied by a change in PPF, implicating a postsynaptic expression mechanism. Our experiments further provide evidence showing the involvement of protein phosphatases because LTD was blocked by bath application of either okadaic acid or calyculin A, selective inhibitors of PP1 and PP2A. These results are consistent with a model presented by Lisman (1989) in which modest elevation of postsynaptic $\mathrm{Ca}^{2+}$ may preferentially activate protein phosphatases (Mulkey et al., 1993; Kirkwood and Bear, 1994) leading to a persistent dephosphorylation of AMPA receptors and subsequently resulting in the reduction of EPSP. This hypothesis received a direct support from a neurochemical study showing that induction of LTD produced a persistent dephosphorylation of the GluR1 subunit of AMPA receptors at serine 845 (Lee et al., 1998).

\section{Loss of LTD in kindled slices}

One of the central findings in this study is the minimum or lack of LTD in the kindled slices. In general, LTD could be blocked by (1) a decrease in the rise of intracellular $\mathrm{Ca}^{2+}$ either through inhibition of $\mathrm{Ca}^{2+}$ influx via NMDA receptors or voltagedependent $\mathrm{Ca}^{2+}$ channels or through inhibition of $\mathrm{Ca}^{2+}$ release from intracellular stores, and (2) an inhibition of $\mathrm{Ca}^{2+}$ dependent processes responsible for LTD formation (Linden and Connor, 1995; Bear and Abraham, 1996). Particularly, in a pathway in which LTD was dependent on the NMDA receptor acti- 
vation, this often occurred via modulation of calcium signal generated by NMDA receptor channels. However, in the present study, we found that neurons from kindled animals were deficient in LTD, which was in the opposite direction of what we expected because, in hippocampal neurons, kindled animals exhibit an upregulation of $\mathrm{Ca}^{2+}$ influx through NMDA receptors (Martin et al., 1992; Kohr et al., 1993). In addition, mGluR-induced depolarization in BLA neurons was increased in amplitude after amygdala kindling (Keele et al., 1997). Therefore, the lack of LTD in the kindled slices could not be accounted by the attenuated NMDA responses. One testable hypothesis to explain this phenomenon is that, because of the upregulation of NMDA responses, LFS evoked a larger rise of $\mathrm{Ca}^{2+}$ in kindled neurons. With this magnitude of intracellular $\mathrm{Ca}^{2+}$ elevation, both phosphatases and kinases were activated, and the effect on synaptic plasticity was cancelled (Linden and Connor, 1995; Cummings et al., 1996). In support of this hypothesis, previous studies analyzing the size of EPSPs evoked by fixed stimulus intensity have revealed a significantly larger amplitude of both NMDA- and AMPA-mediated EPSPs in kindled neurons at each stimulus intensity (Rainnie et al., 1992). Alternatively, calcium-dependent processes downstream of $\mathrm{Ca}^{2+}$ entry may change after kindling.

Interestingly, it has been shown previously that synaptic plasticity was disrupted in electrically induced seizures slices (Moore et al., 1993; Stewart and Reid, 1993). Regardless of underlying mechanisms, the present results provide an explanation for the deficits in memory performance in kindled rats (Sutula et al., 1995), given that LTD together with LTP is regarded as cellular substrate for learning and memory (Bliss and Collingridge, 1993).

Weiss et al. (1995) recently reported that LFS of the amygdala inhibited the development and expression of amygdala kindled seizures, an effect they termed quenching. In the present study, we use the similar stimulating protocol but failed to observe a quenching phenomenon. The discrepancy between the in vivo and in vitro results is not clear. However, despite apparent discrepancy that may relate to the different nature of the preparations, agerelated factors could not account for the loss of LTD because sham-operated, as well as age-matched control, rats did exhibit LTD. Finally, we should emphasize that it is entirely possible that other protocols that we have not examined may produce LTD in the in vitro slices from kindled animals.

In conclusion, this study is the first demonstration of enduring synaptic depression induced by LFS in the naïve amygdala slices. This finding may be of clinical significance in view of the facts that both kindling and fear conditioning resulted in a sustained enhancement of excitatory synaptic transmission in the amygdala, and patients with complex partial seizures of temporal lobe origin may experience behavioral disorders, such as depressive and anxiety-related symptoms (Adamec, 1990). Additional studies of varying stimulation frequency and duration to optimize the conditions for eliciting LTD in kindled slices are warranted.

\section{REFERENCES}

Adamec R (1990) Kindling, anxiety and limbic epilepsy: human and animal perspectives. In: Kindling 4 (Wada JA, ed), pp. 329-341. New York: Plenum.

Bear MF, Abraham WC (1996) Long-term depression in hippocampus. Annu Rev Neurosci 19:437-462.

Bliss TVP, Collingridge GL (1993) A synaptic model of memory: longterm potentiation in the hippocampus. Nature 361:31-39.

Bolshakov VY, Siegelbaum SA (1994) Postsynaptic induction and presynaptic expression of hippocampal long-term depression. Science 264:1148-1152.
Carlsen J (1989) New perspectives on the functional anatomical organization of the basolateral amygdala. Acta Neurol Scand 79:5-27.

Chapman PF, Bellavance LL (1992) Induction of long-term potentiation in the basolateral amygdala does not depend on NMDA receptor activation. Synapse 11:310-318.

Cummings JA, Mulkey RM, Nicoll RA, Malenka RC (1996) $\mathrm{Ca}^{++}$ signaling requirements for long-term depression in the hippocampus. Neuron 16:825-833.

Davis M, Rainnie D, Cassell M (1994) Neurotransmission in the rat amygdala related to fear and anxiety. Trends Neurosci 17:208-214.

Dudek SM, Bear MF (1992) Homosynaptic long-term depression in area CA1 of hippocampus and effects of $N$-methyl-D-aspartate receptor blockade. Proc Natl Acad Sci USA 89:4363-4367.

Gean PW, Shinnick-Gallagher P, Anderson AC (1989) Spontaneous epileptiform activity and alteration of GABA- and of NMDA-mediated neurotransmission in amygdala neurons kindled in vivo. Brain Res 494:177-181.

Gean PW, Chang FC, Huang CC, Lin JH, Way LJ (1993) Long-term enhancement of EPSP and NMDA receptor-mediated synaptic transmission in the amygdala. Brain Res Bull 31:7-11.

Goddard GV, McIntyre DC, Leech DEA (1969) A permanent change in brain function resulting from daily electrical stimulation. Exp Neurol 25:295-330.

Houamed KM, Kuijper JL, Haldeman B, O'Hara PJ, Mulvihill ER, Almers W, Hagen FS (1991) Cloning, expression and gene structure of a G-protein-coupled glutamate receptor from rat brain. Science 252:1318-1321.

Kato N (1993) Dependence of long-term depression on postsynaptic metabotropic glutamate receptors in visual cortex. Proc Natl Acad Sci USA 90:3650-3654.

Keele NB, Arvanov VL, Shinnick-Gallagher P (1997) Quisqualatepreferring metabotropic glutamate receptor activates $\mathrm{Na}^{+}-\mathrm{Ca}^{++}$exchange in rat basolateral amygdala neurones. J Physiol (Lond) 499:87-104.

Kerr DS, Abraham WC (1995) Cooperative interactions among afferents govern the induction of homosynaptic long-term depression in the hippocampus. Proc Natl Acad Sci USA 92:11637-11641.

Kirkwood A, Bear MF (1994) Homosynaptic long-term depression in the visual cortex. J Neurosci 14:3404-3412.

Kohr G, De Koninck Y, Mody I (1993) Properties of NMDA receptor channels in neurons acutely isolated from epileptic (kindled) rats. J Neurosci 13:3612-3627.

LeDoux JE, Cicchetti P, Xagoraris A, Romanski LM (1990) The lateral amygdaloid nucleus: sensory interface of the amygdala in fear conditioning. J Neurosci 10:1062-1069.

Lee HK, Kameyama K, Huganir RL, Bear MF (1998) NMDA induces long-term synaptic depression and dephosphorylation of the GluR1 subunit of AMPA receptors in hippocampus. Neuron 21:1151-1162.

Li H, Weiss SRB, Chuang DM, Post RM, Rogawski MA (1998) Bidirectional synaptic plasticity in the rat basolateral amygdala: characterization of an activity-dependent switch sensitive to the presynaptic metabotropic glutamate receptor antagonist $2 S$ - $\alpha$-ethylglutamic acid. J Neurosci 18:1662-1670.

Linden DJ, Connor JA (1995) Long-term synaptic depression. Annu Rev Neurosci 18:319-357.

Lisman J (1989) A mechanism for the Hebb and the anti-Hebb processes underlying learning and memory. Proc Natl Acad Sci USA 86:9574-9578.

Loscher W, Ebert U, Wahnschaffe U, Rundfeldt C (1995) Susceptibility of different cell layers of the anterior and posterior part of the piriform cortex to electrical stimulation and kindling: comparison with the basolateral amygdala and "area tempestas." Neuroscience 66:265-276.

Manabe T, Wylle DJ, Perkel DJ, Nicoll RA (1993) Modulation of synaptic transmission and long-term potentiation: effect on paired pulse facilitation and EPSC variance in the CA1 region of the hippocampus. J Neurophysiol 70:1451-1459.

Maren S, Fanselow MS (1995) Synaptic plasticity in the basolateral amygdala induced by hippocampal formation stimulation in vivo. J Neurosci 15:7548-7564.

Martin D, McNamara JO, Nadler JV (1992) Kindling enhances sensitivity of CA3 hippocampal pyramidal cells to NMDA. J Neurosci 12:1928-1935.

Masu M, Tanabe Y, Tsuchida K, Shigemoto R, Nakanishi S (1991) Sequence and expression of a metabotropic glutamate receptor. Nature 349:760-765. 
McKernan MG, Shinnick-Gallagher P (1997) Fear conditioning induces a lasting potentiation of synaptic currents in vitro. Nature 390:607-610.

McNamara JO (1986) Kindling model of epilepsy. Adv Neurol 44:303-318.

Moore SD, Barr DS, Wilson WA (1993) Seizure-like activity disrupts LTP in vitro. Neurosci Lett 163:117-119.

Mulkey RM, Malenka RC (1992) Mechanisms underlying induction of homosynaptic long-term depression in area CA1 of the hippocampus. Neuron 9:967-975.

Mulkey RM, Herron CE, Malenka RC (1993) An essential role for protein phosphatases in hippocampal long-term depression. Science 261:1051-1055.

Munkenbeck KE, Schwark WS (1982) Serotonergic mechanism in amygdaloid-kindled seizures. Exp Neurol 76:246-253.

Oliet SHR, Malenka RC, Nicoll RA (1997) Two distinct forms of longterm depression coexist in CA1 hippocampal pyramidal cells. Neuron 18:1294-1297.

Ottersen OP (1982) Connections of the amygdala of the rat. IV. Corticoamygdaloid and intraamygdaloid connections as studied with axonal transport of horseradish peroxidase. J Comp Neurol 205:30-48.

Overstreet LS, Pasternak JF, Colley PA, Slater NT, Trommer BL (1997) Metabotropic glutamate receptor mediated long-term depression in developing hippocampus. Neuropharmacology 36:831-844.

Paxinos G, Watson C (1982) The rat brain in stereotaxic coordinates. San Diego: Academic.

Pitkanen A, Savander V, LeDoux JE (1997) Organization of intraamygdaloid circuitries in the rat: an emerging framework for understanding functions of the amygdala. Trends Neurosci 20:517-522.

Racine RJ (1972) Modification of seizure activity by electrical stimulation. II. Motor seizure. Electroencephalogr Clin Neurophysiol 32:281-294.
Rainnie DG, Asprodini EK, Shinnick-Gallagher P (1992) Kindlinginduced long-lasting changes in synaptic transmission in the basolateral amygdala. J Neurophysiol 67:443-454.

Rogan MT, Staubli UV, LeDoux JE (1997) Fear conditioning induces associative long-term potentiation in the amygdala. Nature 390:604-607.

Schulz PE, Cook EP, Johnston P (1994) Changes in paired-pulse facilitation suggest presynaptic involvement in long-term potentiation. J Neurosci 14:5325-5337.

Stafanacci L, Farb CR, Pitanen A, Go G, LeDoux JE, Amaral DG (1992) Projections from the lateral nucleus to the basal nucleus of the amygdala: a light and electron microscopic PHA-L study in the rat. J Comp Neurol 323:586-601.

Stewart C, Reid I (1993) Electroconvulsive stimulation and synaptic plasticity in the rat. Brain Res 620:139-141.

Sutula T, Lauersdorf S, Lynch M, Jurgella C, Woodard A (1995) Deficits in radial arm maze performance in kindled rats: evidence for longlasting memory dysfunction induced by repeated brief seizures. J Neurosci 15:8295-8301.

Wagner JJ, Alger BE (1995) GABAergic developmental influences on homosynaptic LTD and depotentiation in rat hippocampus. J Neurosci 15:1577-1586.

Weiss SRB, Li X, Rosen JB, Li H, Heynen T, Post RM (1995) Quenching: inhibition of development and expression of amygdala kindled seizures with low frequency stimulation. NeuroReport 4:2171-2176.

Weisskopf MG, LeDoux JE (1999) Distinct populations of NMDA receptors at subcortical and cortical inputs to principal cells of the lateral amygdala. J Neurophysiol 81:930-934.

Zucker RS (1989) Short-term synaptic plasticity. Annu Rev Neurosci 12:13-31. 